\title{
OTIMIZAÇÃO NOS PADRÕES DE CORTE DE CHAPAS DE FIBRA DE MADEIRA RECONSTITUÍDA: UM ESTUDO DE CASO
}

\author{
Luciano Belluzzo \\ Reinaldo Morabito * \\ Departamento de Engenharia de Produção \\ Universidade Federal de São Carlos (UFSCar) \\ São Carlos - SP \\ lbelluzzo@bebidasipiranga.com.br \\ morabito@power.ufscar.br
}

* Corresponding author / autor para quem as correspondências devem ser encaminhadas

Recebido em 06/2004; aceito em 06/2005 após 1 revisão

Received June 2004; accepted June 2005 after one revision

\begin{abstract}
Resumo
Fábricas de chapas de fibra de madeira reconstituída (hardboards) transformam eucalipto em chapas retangulares por meio de processos de desagregação, prensagem e secagem. Estas chapas são então cortadas em chapas retangulares menores para atender às demandas de clientes. A programação do processo de corte é uma atividade importante no planejamento e controle da produção dessas empresas devido aos altos custos envolvidos com as perdas do material cortado. Neste artigo apresentamos abordagens para gerar padrões de corte que minimizem as perdas de material, satisfazendo as restrições dos equipamentos de corte e a demanda dos clientes. Propomos um algoritmo baseado em programação dinâmica, que pode ser combinado com simples heurísticas construtivas gulosas ou com o algoritmo primal simplex com geração de colunas. Um estudo de caso foi realizado em uma grande empresa do setor, localizada no interior de São Paulo, cujo processo de corte envolve uma tecnologia com alto nível de automação. Os resultados mostram que as abordagens têm potencial para gerar boas soluções comparadas com as utilizadas pela empresa.
\end{abstract}

Palavras-chave: problemas de corte; programação dinâmica; indústria de hardboard.

\begin{abstract}
Hardboard factories transform eucalyptus into rectangular plates by means of processes of disintegration, pressing and drying. These plates are then cut into smaller rectangular plates to satisfy customer demands. The scheduling of the cutting process is an important activity of the production planning and control of these companies due to the high costs related to trim losses. In this paper we present approaches to generate cutting patterns that minimize the waste of material, satisfying the constraints of the cutting equipment and the customer demands. We propose an algorithm based on dynamic programming, which can be combined with simple greedy constructive heuristics or the simplex primal algorithm with column generation. A case study was carried out in a large hardboard company located in Sao Paulo State, whose cutting process involves a technology with high degree of automation. The results show that the approaches have potential to produce good solutions compared to the ones utilized by the company.
\end{abstract}

Keywords: cutting problems; dynamic programming; hardboard industry. 


\section{Introdução}

Neste trabalho estudamos o problema de corte em fábricas de chapas de fibra de madeira reconstituída, também chamadas chapas duras (hardboards). Nestas fábricas, toras de eucalipto (das espécies grants e saligma) são desagregadas, prensadas e secadas para produzir as chapas duras. Estas chapas são então cortadas em chapas retangulares menores encomendadas por clientes, por exemplo, fábricas de móveis e montadoras de veículos. A programação do processo de corte é uma atividade importante no planejamento e controle da produção devido aos custos das perdas do material cortado e ao impacto na produtividade destas empresas.

O problema de corte consiste, basicamente, em determinar a "melhor" forma de cortar as chapas duras (objetos), de maneira a produzir as unidades menores (itens) com a menor perda possível de material. Devido à programação dos equipamentos de corte e à escala de produção, as perdas podem chegar a toneladas por dia, o que resulta em custos significativos. Tais perdas referem-se a restos de chapas duras de boa qualidade que se tornam inúteis, devido às suas dimensões resultarem muito pequenas para uso prático. Parte destas perdas pode ser evitada apenas melhorando a programação da produção dos equipamentos de corte, o que não implica em quaisquer investimentos adicionais em capacidade.

Problemas de corte (e empacotamento) têm sido extensivamente tratados nas literaturas de gerência da produção e pesquisa operacional, e aparecem em diversos processos industriais onde os objetos, em geral disponíveis em estoque, correspondem a barras de aço, bobinas de papel e alumínio, chapas metálicas e de madeira, placas de circuito impresso, lâminas de vidro e fibra de vidro, peças de couro, etc., e os itens, com dimensões especificadas, são em geral encomendados através de uma carteira de pedidos de clientes. Estudos destes problemas podem ser encontrados nos exames e edições especiais em Dyckhoff (1990), Dowsland \& Dowsland (1992), Sweeney \& Parternoster (1992), Dyckhoff \& Finke (1992), Morabito \& Arenales (1992), Martello (1994), Bischoff \& Waescher (1995), Dyckhoff et al. (1997), Arenales et al. (1999), Wang \& Waescher (2002), Hifi (2002) e Lodi et al. (2002), e nas bases de dados do SICUP (2004) (Special Interest Group on Cutting and Packing). Devido à diversidade de casos em que os problemas podem aparecer na prática, e à complexidade dos algoritmos exatos (os problemas são em geral NP-difíceis), a maioria dos trabalhos encontrados na literatura apresenta abordagens heurísticas.

Um estudo de caso foi realizado em uma grande empresa do setor, localizada no interior de São Paulo, cujo processo de corte envolve uma tecnologia com alto nível de automação: a serra Holzma. Devido às restrições impostas por este equipamento, os cortes são do tipo guilhotinado com até 3 estágios, existe limitações para as dimensões das chapas e dos cortes longitudinais e transversais, além de outras considerações como: cortes de cabeça e giro do pacote de chapas, número de estações de descarregamento automáticas e manuais, e grandezas das incisões das serras, remates e margens do retrim.

Para resolver este problema de corte, apresentamos abordagens baseadas na aplicação de técnicas de programação dinâmica para a geração de padrões de corte, similarmente a Morabito \& Garcia (1998a). Convém salientar que, devido às restrições particulares do equipamento de corte, os modelos clássicos conhecidos da literatura não representam satisfatoriamente o presente problema. Além disso, não foram encontrados trabalhos tratando especificamente deste caso particular, tampouco trabalhos tratando de outras aplicações que pudessem ser aqui diretamente utilizados. Os estudos em Yanasse et al. (1991) e Morabito \& 
Garcia (1998a, 1998b) também tratam de problemas de corte nas indústrias de madeira e chapas duras, porém envolvendo equipamentos de corte com algumas características e restrições diferentes da serra Holzma. A principal contribuição do presente trabalho é o algoritmo de programação dinâmica para gerar padrões de corte de mínima perda satisfazendo as restrições especiais desta serra.

Este artigo está organizado da seguinte maneira: na próxima seção, discutimos brevemente o processo de produção de chapas duras, com ênfase no processo de corte e nas características e restrições da serra. $\mathrm{Na}$ seção 3, revisamos duas abordagens de solução conhecidas da literatura para problemas de corte, o algoritmo primal simplex com geração de colunas (Gilmore \& Gomory, 1965) e uma simples heurística construtiva gulosa (Hinxman, 1980). Em seguida, propomos fórmulas recursivas de programação dinâmica para serem combinadas nestas abordagens e gerar padrões de corte factíveis para a serra. Na seção 4, para ilustrar a viabilidade do uso deste algoritmo de programação dinâmica, resolvemos um exemplo real da fábrica de chapas duras aplicando as duas abordagens acima acopladas com este gerador de padrões, e comparamos a solução obtida com a solução utilizada pela empresa. Também resolvemos diversos exemplos aleatórios de geração de padrões, para avaliar isoladamente o desempenho do algoritmo de programação dinâmica. Finalmente, na seção 5, apresentamos as conclusões e as perspectivas para pesquisa futura.

\section{Processo de Produção}

Conforme mencionado, as chapas de fibra de madeira reconstituída (chapas duras) são formadas por processos de desintegração da madeira de eucalipto e reconstituição e prensagem com componentes químicos. Inicialmente, toras de eucalipto das espécies grants e saligma são cortadas na floresta e transportadas por meio de caminhões até a fábrica, onde são pesadas e encaminhadas para a casa de cavacos. Na casa de cavacos as toras são lavadas em uma cortina de água para retirar impurezas e principalmente areia, para não danificar os equipamentos e o processo. Depois de lavadas, as toras entram em um equipamento denominado chipper (picador), que pica as toras em pequenos pedaços denominados cavacos, que depois são estocados em grandes montes ao ar livre. Os cavacos devem ter tamanhos uniformes, caso contrário, podem ocorrer problemas no pré-aquecimento, cuja função é amolecer a lignina (cola natural que une as fibras da madeira).

Os cavacos são transportados por esteiras rolantes até os desfibradores, que transformam os cavacos em fibras separadas. Esta separação é feita por meio de um processo termomecânico. Neste processo, os cavacos passam primeiramente por um pré-aquecedor, que amolece a lignina por meio da aplicação de vapor a uma certa pressão. Após esse tratamento, as fibras são separadas por cisalhamento, pela passagem dos cavacos entre dois discos ranhurados, sendo um deles fixo e o outro giratório. O processo de desfibração e a qualidade da matéria-prima são fundamentais para a formação da polpa. As fibras são então diluídas em água, num sistema de tanques, formando uma polpa que irá alimentar a formadora. A formadora é um filtro contínuo que produz um colchão de fibras, separando-as da água em que estavam diluídas. Este colchão é cortado em tamanho adequado e alimenta a prensa. $\mathrm{Na}$ formadora inclui-se aditivos que modificam as propriedades tecnológicas das chapas. Combinando-se a vazão de polpa com a velocidade de formação do colchão, consegue-se controlar a espessura do mesmo, que juntamente com a pressão de prensagem, definem a espessura e a densidade das chapas. 
A prensa aplica pressão e temperatura nos colchões, retirando toda a água e assentando as fibras. É importante que as fibras se encontrem entrelaçadas, pois assim obtém-se um produto com melhores propriedades mecânicas (consegue-se um maior entrelaçamento das fibras evitando fluxo laminar da polpa na formadora). Depois de prensados, os colchões (já denominados chapas) passam por um tratamento térmico, onde se reativa a lignina e a chapa adquire as propriedades tecnológicas finais. Após o tratamento térmico, as chapas sofrem ainda um tratamento de umidificação que equilibra sua umidade com a do meio ambiente (do destino do produto), para evitar empenamento. Têm-se então as chamadas chapas base (ou chapas duras) que, em função da demanda, são serradas em chapas menores (itens), lixadas, acondicionadas e expedidas em uma área denominada final de linha.

Para mais detalhes do processo de produção de chapas duras, os leitores podem consultar Garcia (1996) e Belluzzo (2002).

\subsection{Processo de corte}

Em estudos anteriores (Morabito \& Garcia, 1998a, 1998b) abordagens foram propostas para otimizar a programação da produção do processo de corte da mesma fábrica de chapas duras. Desde então, este processo e sua programação sofreram alterações. $\mathrm{O}$ equipamento de corte anterior, chamado serra Samba e com capacidade de corte de 15 a 20 toneladas por hora de material, foi desativado e substituído por outro mais moderno, chamado serra Holzma (Figura 1) e com capacidade de corte de $45 \mathrm{t} / \mathrm{h}$. A programação, que antes era feita manualmente, passou a ser realizada e controlada por computador, com os padrões de corte gerados por um software específico (cut height) fornecido pelo fabricante do equipamento.

A serra Holzma é constituída por um conjunto de duas serras longitudinais e duas serras transversais: uma serra circular de grande diâmetro, que faz o corte propriamente dito, e outra serra circular de pequeno diâmetro, que abre o sulco de corte. Cada uma das pequenas serras caminha na frente das serras de maior diâmetro. $\mathrm{O}$ equipamento é alimentado por um pacote de chapas duras (book), e possui um sistema de transporte do pacote totalmente computadorizado, e um sistema de giro do pacote, que permite o corte de padrões mais complexos. À medida que os itens dos padrões são cortados, eles são encaminhados por esteiras rolantes para estações de descarregamento. Ao todo são cinco estações, sendo quatro automáticas e uma manual. As quatro estações automáticas possuem também alimentadores de paletes (Figura 1).

Diferente da serra Samba, que cortava apenas padrões guilhotinados 2-estágios, a serra Holzma corta padrões guilhotinados 3-estágios (ver adiante) por possuir o sistema de giro do pacote. Todos os seus componentes, desde a alimentação do pacote até o descarregamento dos itens nas estações automáticas, são controlados por computador, diminuindo a quase zero os tempos de preparação. As ordens de fabricação contendo quantidades, espessura, tipo de chapa dura a ser utilizada, nome do cliente, tipo de despacho, com paletes ou sem paletes (pacote), etc., alimentam o software da serra. Este software gera os padrões a serem cortados (não temos conhecimento dos seus métodos de otimização) e os envia para o computador que controla a serra. Estes padrões em geral são eficientes, mas não é raro o operador do equipamento alterá-los para aumentar seus rendimentos. A empresa freqüentemente limita os padrões a no máximo 1 corte de cabeça (ver adiante), diminuindo assim a complexidade dos padrões em favor da produtividade do equipamento. 


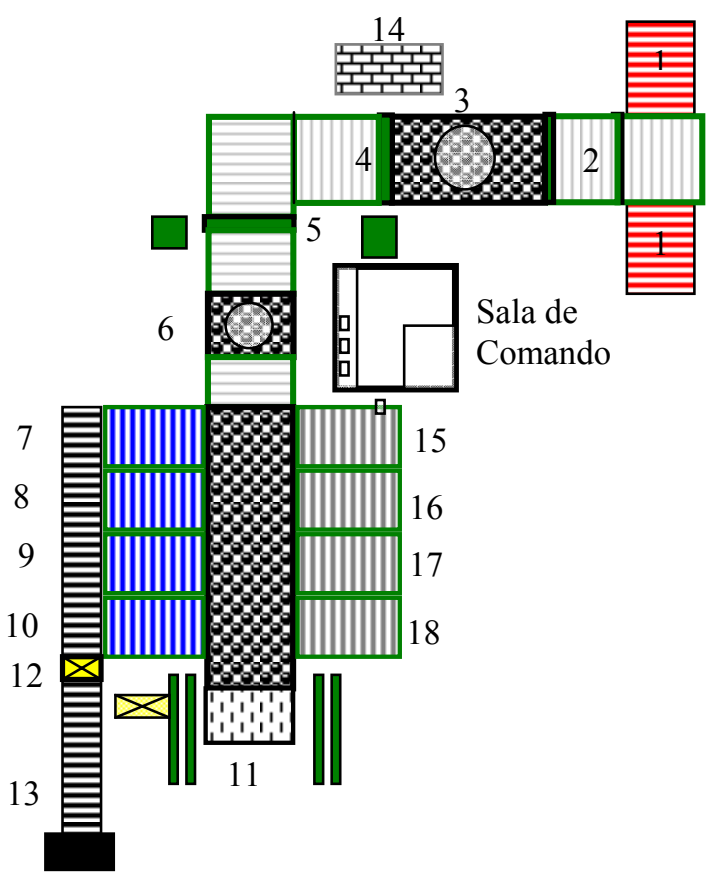

Legenda:

1- Alimentadores

2- Formação do pacote (book) de chapas

3- Sistema de giro das chapas

4- Serra longitudinal

5- Serra transversal

6- Girador de pacote

7- Estação de descarregamento automática 1

8- Estação de descarregamento automática 2

9- Estação de descarregamento automática 3

10- Estação de descarregamento automática 4

11- Estação de descarregamento manual

12- Girador para cintamento de pacote

13- Transportador de pacotes

14- Desintegrador de resíduos

15- Alimentador de paletes para estação de descarga 1

16- Alimentador de paletes para estação de descarga 2

17- Alimentador de paletes para estação de descarga 3

18- Alimentador de paletes para estação de descarga 4

Figura 1 - Esquema da serra Holzma.

\subsection{Restrições do processo de corte}

\section{Chapas duras e cortes longitudinais e transversais}

As chapas duras são produzidas em diferentes dimensões nas três linhas de produção da empresa (Tabela 1), com espessuras variando de 2,5 a 6,4 milímetros. A serra Holzma pode ser alimentada somente por chapas duras com dimensões dentro dos intervalos mostrados na Tabela 2. A quantidade de chapas duras em estoque em geral é suficientemente grande (em relação à demanda de itens da carteira de pedidos), podendo ser considerada ilimitada para efeito da programação da produção da serra. Os cortes que podem ser feitos pelas serras longitudinais e transversais são sempre do tipo guilhotinados (i.e., um corte que divide um retângulo em dois retângulos) e possuem dimensões máximas e mínimas. As serras longitudinais produzem os cortes ao longo do comprimento das chapas duras. No caso de giro de $90^{\circ}$ das chapas, também produzem os cortes de cabeça (veja adiante), isto é, ao longo do comprimento das cabeças. As serras transversais produzem os cortes ao longo da largura das chapas duras e, no caso de giro de $90^{\circ}$ das chapas, também produzem os cortes dentro de cada cabeça (i.e., ao longo da largura de cada cabeça). Os comprimentos máximos para os cortes são restritos pelas larguras da serra Holzma. Os comprimentos mínimos são restritos pelos espaçamentos dos roletes transportadores, garras de transportes e fixadores (Tabela 3). 
Tabela 1 - Características das linhas de produção.

\begin{tabular}{c|cc}
\hline Linha de produção & Dimensões das chapas duras $(\mathrm{mm})$ & Produção (t/dia) \\
\hline PS I & $4880 \times 2130$ & 240 \\
PS II & $5500 \times 2130$ & 270 \\
PS III & $7300 \times 1100$ & 210 \\
\hline
\end{tabular}

Tabela 2 - Limites mínimos e máximos das dimensões das chapas duras.

\begin{tabular}{c|cc}
\hline & Mínimo $(\mathrm{mm})$ & Máximo $(\mathrm{mm})$ \\
\hline Comprimento & 4860 & 5580 \\
Largura & 2130 & 2170 \\
\hline
\end{tabular}

Tabela 3 - Limites mínimos e máximos dos cortes longitudinais e transversais.

\begin{tabular}{c|cc}
\hline & Mínimo $(\mathrm{mm})$ & Máximo $(\mathrm{mm})$ \\
\hline Comprimento do corte longitudinal & 200 & 5600 \\
Comprimento do corte transversal & 100 & 2200 \\
\hline
\end{tabular}

\section{Cortes de cabeça}

O uso dos chamados cortes de cabeça em geral reduz as perdas dos padrões de cortes, mas em contra partida, aumenta os tempos das operações de corte. Os cortes de cabeça são os cortes verticais guilhotinados ao longo da largura da chapa dura, que a separam em parte principal e cabeças (Figura 2). Cada cabeça tem comprimento igual à largura da chapa dura, e largura igual à largura de uma ou mais faixas verticais. Ou seja, uma cabeça pode conter apenas uma faixa com itens de mesma largura desta faixa (e.g., as cabeças 1, 2, 3 e 5 da Figura 2), ou várias faixas com uma solução homogênea: itens iguais arranjados na forma de tabuleiro (e.g., a cabeça 4 da Figura 2). A serra pode produzir padrões com no máximo 5 cortes de cabeça. Note que a solução homogênea é considerada apenas como uma cabeça, apesar de envolver várias faixas, mas o procedimento de corte é igual às demais cabeças.

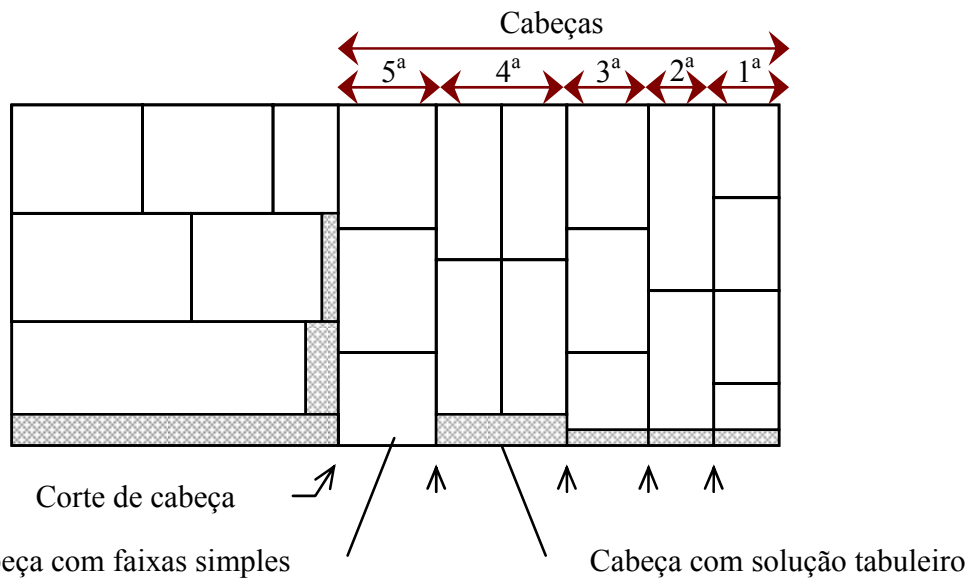

Figura 2 - Múltiplos cortes de cabeça. 
Após cada corte de cabeça, a parte principal deve ter comprimento maior ou igual a 1000 $\mathrm{mm}$. Essa restrição é devida ao sistema de garras que movimenta o pacote de chapas duras. Se a parte principal possuir comprimento inferior a $1000 \mathrm{~mm}$, as garras não conseguem alinhar o pacote principal. Para que haja o corte de cabeça, o pacote de chapas duras é girado em $90^{\circ}$ no sentido horário. Se não houver mais cortes de cabeça, o pacote principal sofre uma rotação de $90^{\circ}$ completando o giro. Na Figura 3, $x$ indica o comprimento do pacote principal e $y$ é o comprimento da seção de cabeça composta de uma simples cabeça. Note que $y$ deve ter comprimento menor que $2200 \mathrm{~mm}$; caso contrário, a cabeça não poderia ser cortada na serra transversal, com comprimento de corte máximo de $2200 \mathrm{~mm}$, conforme a Tabela 3.

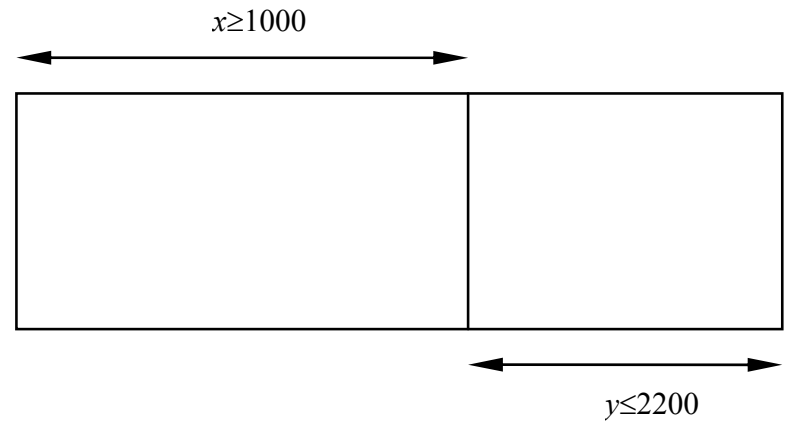

Figura 3 - Limites para um corte de cabeça.

\section{Giro do pacote (book)}

O equipamento pode ou não girar o pacote de chapas duras. $\mathrm{O}$ giro é executado por um conjunto de roldanas situadas antes da serra longitudinal. O equipamento executa, no máximo, um giro completo. $\mathrm{O}$ giro permite que se cortem padrões com até 3 estágios (Figura 4), diminuindo assim as perdas de material. Num primeiro estágio, cortes guilhotinados são produzidos numa direção da chapa dura e, nos dois estágios sucessivos, cortes guilhotinados são produzidos nas direções opostas (i.e., cortes do estágio subseqüente, perpendiculares aos cortes do estágio antecessor). Para se cortar padrões 3-estágios é necessário que ocorra o giro, pois são os cortes de cabeça (verticais) que permitem o terceiro estágio. Estes cortes de cabeça são produzidos somente se o pacote sofrer o giro. Desta maneira, apenas uma família particular de padrões 3-estágios pode ser cortada, conforme ilustrado na Figura 4. Sem o giro do pacote, a serra produz apenas padrões guilhotinados com até 2-estágios. Note na Figura 4 que o padrão (b) é infactível porque seu corte de cabeça resulta numa cabeça envolvendo cortes em 2-estágios, e o padrão (c) é infactível porque sua parte principal envolve cortes em 3-estágios.

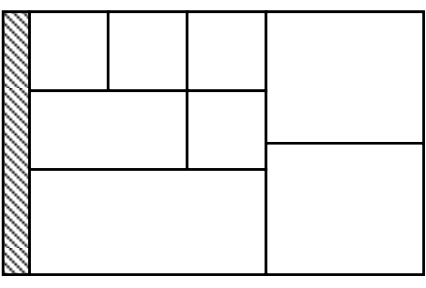

(a) Padrão 3-estágios factível

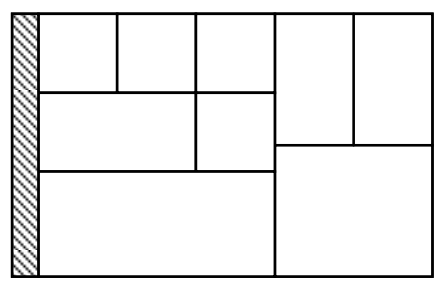

(b) Padrão 3-estágios infactível

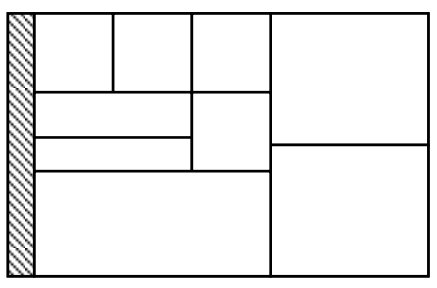

(c) Padrão 3-estágios infactível

Figura 4 - Exemplos de padrões 3-estágios que podem ou não ser cortados pela serra. 


\section{Estações de descarregamento}

O número de estações de descarregamento limita o número de tipos de itens no padrão de corte. Conforme mencionado, das cinco estações de descarregamento da serra, quatro são automáticas e uma é manual. É preferível que o padrão de corte utilize somente as estações automáticas, pois a utilização manual necessita de mão-de-obra para o descarregamento, implicando em custos adicionais. Note que isto implica que cada padrão de corte pode ter no máximo 4 tipos de itens, um para cada estação automática. Além disso, se os alimentadores de paletes das estações automáticas estiverem operando, eles impõem uma restrição adicional: enquanto o palete ainda não estiver completo (sendo carregado por um certo tipo de item), a estação não pode descarregar outro tipo de item. Isto é equivalente a requerer que, dada uma seqüência de padrões de corte, o número máximo de pilhas abertas de itens (uma pilha é aberta quando um tipo de item é cortado pela primeira vez e fechada quando todos os itens deste tipo foram cortados) ao longo desta seqüência deve ser no máximo igual a 4, isto é, uma pilha para cada alimentador de palete. Esta restrição pode ser desconsiderada se os alimentadores de paletes não estiverem operando; neste caso os padrões devem ter preferencialmente até 4 tipos de itens. Se a estação manual estiver em uso, estas duas restrições podem ser relaxadas e os padrões podem ter qualquer número de tipos de itens.

\section{Incisão (espessura) da serra, remates e margem do retrim}

A incisão é o montante de material removido pela espessura da lâmina da serra ao se cortar o material. As serras circulares utilizadas pela empresa removem $6 \mathrm{~mm}$ de material da chapa dura para cada linha de corte. Os remates são para aparar as bordas das chapas duras. Utilizase remates mínimos no comprimento, tanto para frente (borda de ataque) como para traseira da chapa dura, de $20 \mathrm{~mm}$ (já com a incisão de serra) (Figura 5). Um remate de $20 \mathrm{~mm}$ com uma espessura de serra de $6 \mathrm{~mm}$ remove $14 \mathrm{~mm}$ de material mais $6 \mathrm{~mm}$ gastos na incisão da serra, totalizando $20 \mathrm{~mm}$ de material da chapa dura. Em alguns casos, não são requeridos remates na frente ou na traseira da chapa dura, ou em ambos.

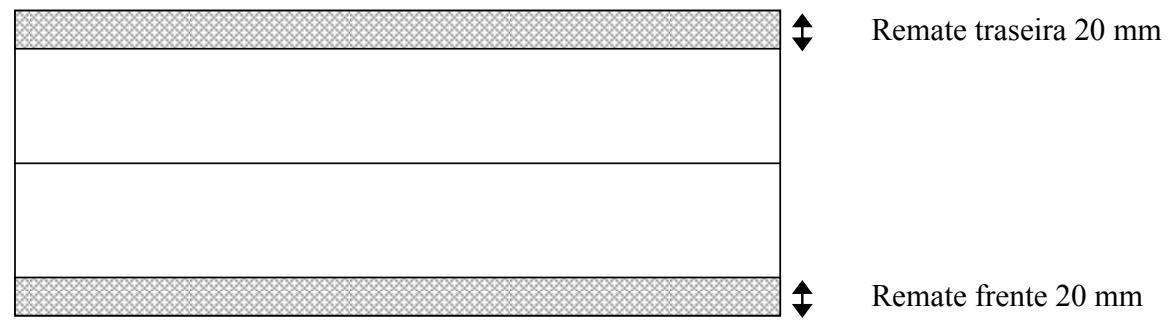

Figura 5 - Remates de frente e traseira.

Remates mínimos na frente e na traseira de cada chapa dura também são especificados para o corte transversal (Figura 6). Estes remates são para aparar as bordas de uma tira. Utiliza-se remate de $17 \mathrm{~mm}$ para cada lado da chapa dura nos cortes transversais (já com a espessura da serra). Um remate de $17 \mathrm{~mm}$ com uma espessura de serra de $6 \mathrm{~mm}$ remove $11 \mathrm{~mm}$ de material da chapa dura, mais $6 \mathrm{~mm}$ com a serra, totalizando $17 \mathrm{~mm}$ de material da chapa dura. O retrim é o remate interno que pode ser usado em cada porção da chapa dura, após a chapa ter sido dividida por um corte de cabeça. A serra executa um retrim na porção principal da chapa dura (Figura 7). Utiliza-se um retrim de $20 \mathrm{~mm}$. 


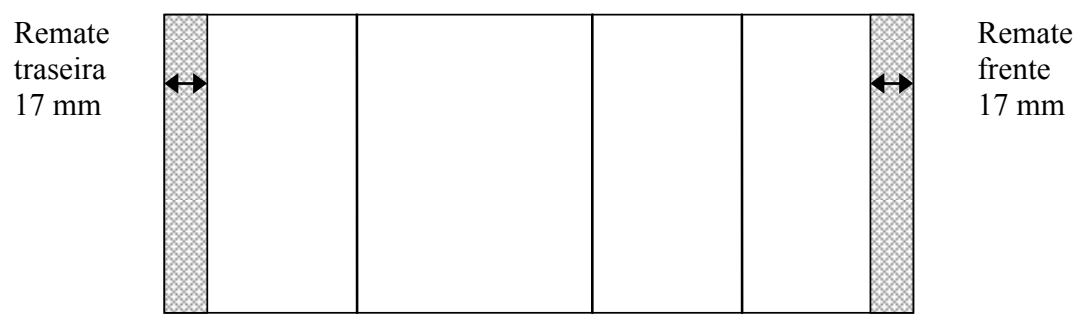

Figura 6 - Remates de cortes cruzados: frente, traseira.

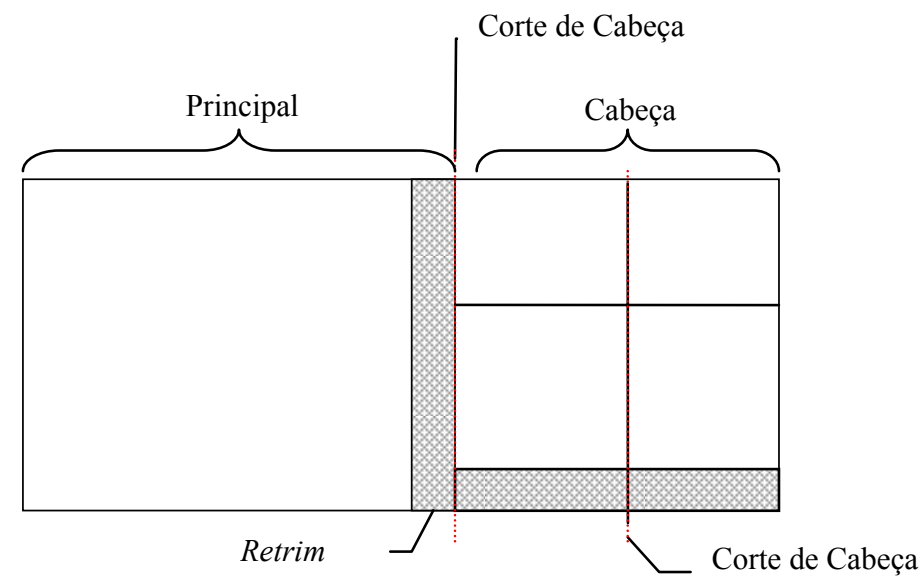

Figura 7 - Retrim para cabeça de tabuleiro.

Em resumo, as restrições do processo de corte a serem consideradas neste trabalho são:

(i) Cortes longitudinais e transversais do tipo guilhotinado, com comprimentos mínimos e máximos.

(ii) Corte de cabeça produzindo uma faixa com itens de mesma largura, ou várias faixas com itens iguais arranjados na forma de tabuleiro (solução homogênea), com larguras menores ou iguais a $2200 \mathrm{~mm}$. O comprimento da parte principal deve ser menor ou igual a $1000 \mathrm{~mm}$. A serra pode produzir padrões com no máximo 5 cortes de cabeça.

(iii) Giro do pacote produzindo uma família particular de padrões 3-estágios factíveis para a serra.

(iv) Número máximo de 4 tipos de itens diferentes por padrão, imposto pelo número de estações de descarregamento automáticas. Se os alimentadores de paletes das estações automáticas estiverem operando, o número máximo de pilhas de itens abertas (ao longo da seqüência de padrões de corte) deve ser no máximo igual a 4 . Se a estação de descarregamento manual estiver operando, estas duas restrições podem ser ignoradas e os padrões podem ter qualquer número de tipos de itens.

(v) Espessura de $6 \mathrm{~mm}$ das serras longitudinais e transversais, remates de 20 e $17 \mathrm{~mm}$ e margens do retrim de $20 \mathrm{~mm}$.

Convém salientar que desconhecemos artigos na literatura de problemas de corte tratando este conjunto de restrições. 


\section{Abordagens de Solução}

Para o propósito do presente estudo, nas abordagens a seguir, consideramos todas as restrições discutidas na seção 2 , exceto a dos alimentadores de paletes das estações automáticas. Esta restrição está relacionada com um problema NP-difícil de seqüenciamento de padrões de corte, tratado na literatura como o problema do máximo número de pilhas abertas (maximum open stack problem) (Yuen, 1995; Yanasse, 1997; Ashikaga 2001; Becceneri et al., 2004). Conforme discussão na seção 2, as decisões de seqüenciamento podem ser desconsideradas se os alimentadores de paletes das estações automáticas não estiverem operando, ou se a estação manual estiver operando.

\subsection{Modelagem do problema}

Seja $m$ o número de tipos de itens na carteira de pedidos. Cada item do tipo $i, i=1, . ., m$, tem dimensões $\left(l_{i}, w_{i}\right)$, onde $l_{i}$ e $w_{i}$ denotam o comprimento e a largura, respectivamente. Seja $b_{i}$ a quantidade demandada de itens do tipo $i$. Admitimos que o processo de corte dispõe de um estoque de chapas duras (ou simplesmente chapas) suficientemente grande para produzir todos os $\sum_{i=1}^{m} b_{i}$ itens demandados, conforme discussão na seção 2. Cada chapa tem dimensões $(L, W)$, onde $L$ e $W$ denotam o comprimento e a largura, respectivamente. Sem perda de generalidade (Gilmore \& Gomory, 1965; Morabito \& Arenales, 2000), ao simplesmente adicionarmos nas dimensões $l_{i}, w_{i}, L$ e $W$ a espessura da serra (no caso, $6 \mathrm{~mm}$ ), estamos satisfazendo a restrição de incisão da serra (seção 2).

Por conveniência, considere inicialmente que todos os objetos sejam iguais e todos os possíveis padrões de corte sejam conhecidos. Para cada um destes padrões, digamos para o $j$-ésimo padrão, associamos o vetor $\left(a_{1 j}, a_{2 j}, \ldots, a_{m j}\right)$, onde cada $a_{i j}$ corresponde ao número de vezes que o item do tipo $i$ aparece no padrão $j$. Seja $c_{j}=L W-\sum_{i=1}^{m} l_{i} w_{i} a_{i j}$ a perda de material associada ao padrão $j$ ( $c_{j}$ também pode ser definido como o custo do padrão $j$ ). O problema de corte é formulado pelo seguinte programa linear inteiro:

$$
\begin{aligned}
& \text { (P) } \quad \min \sum_{j} c_{j} x_{j} \\
& \text { s.a. } \quad \sum_{j} a_{i j} x_{j} \geq b_{i}, i=1, \ldots, m
\end{aligned}
$$

com: $x_{j} \geq 0$, inteiro

onde cada variável $x_{j}$ corresponde ao número de vezes que o padrão $j$ é cortado. Em problemas nos quais o número de possíveis padrões resulta muito grande (o que é comum nos casos práticos), o problema (P) é em geral muito difícil de ser resolvido otimamente. Gilmore \& Gomory $(1961,1963,1965)$ sugeriram então:

(i) Relaxar as restrições de integralidade (3) do problema (P);

(ii) Resolvê-lo através do método simplex, partindo de uma base inicial com $m$ padrões e, durante cada iteração do simplex, gerar um novo padrão para substituir um dos $m$ padrões da base. 
Assim, em cada iteração do simplex, resolve-se o subproblema:

(P1) $\max \sum_{i=1}^{m} \pi_{i} a_{i j}$

sujeito à condição de que o vetor $\left(a_{1 j}, a_{2 j}, \ldots, a_{m j}\right)$ corresponde a um padrão $j$ factível.

onde $\pi_{i}$ é a variável dual associada à restrição $i$ do problema $(\mathrm{P})$ para a base atual. $\mathrm{O}$ procedimento termina assim que: $\sum_{i=1}^{m} \pi_{i} a_{i j}-c_{j} \leq 0$. Este procedimento pode ser útil quando a demanda $b_{i}$ é suficientemente grande em relação a cada $a_{i j}$ (como ocorre no presente problema de corte). Nestes casos, simples técnicas de arredondamento da solução relaxada podem ser aplicadas para produzir uma boa solução para o problema (P). Assim, a maior dificuldade é resolver o subproblema (P1).

Alguns autores também sugeriram o uso de heurísticas construtivas gulosas para resolver o problema (P), como alternativas para o procedimento acima. Um exemplo (repeated exhaustion reduction; Hinxman, 1980; Silveira \& Morabito, 2002) é apresentado a seguir:

Enquanto a demanda não for exaurida, faça:

Passo 1: Gere o melhor padrão de corte, ou seja, resolva o subproblema (P1) com $\pi_{i}$ igual ao valor do item $i$ (e.g., a área $l_{i} w_{i}$ ).

Passo 2: Repita este padrão, tanto quanto for possível, em função da demanda dos itens. Ou seja, corte o maior número de vezes possível este padrão, levando em conta a demanda atual dos itens deste padrão.

Passo 3: Atualize a demanda dos itens, ou seja, retire da demanda atual a quantidade de itens que foi cortada no passo 2. Eventualmente inclua na demanda os itens de novos pedidos.

Assim como no procedimento anterior, a maior dificuldade desta heurística gulosa é resolver o subproblema (P1) no passo 1. Uma vantagem destas heurísticas em relação àquele procedimento é que elas são flexíveis para tratar problemas em que a demanda deve ser exatamente satisfeita (i.e., $\sum_{j} a_{i j} x_{j}=b_{i}, i=1, \ldots, m$, ao invés de (2)). Estas heurísticas também são úteis em situações de demanda dinâmica, em que itens de novos pedidos vão sendo incluídos na carteira.

Na seção seguinte, propomos fórmulas recursivas de programação dinâmica para resolver o subproblema (P1) no processo de corte de chapas duras, que, conforme mencionado na seção 1, é a principal contribuição deste trabalho.

\subsection{Programação dinâmica}

Seja $v_{i}$ o valor do item $i$; note que $v_{i}=\pi_{i}$ para gerar padrões para o procedimento de Gilmore $\&$ Gomory, ou $v_{i}=l_{i} w_{i}$ para gerar padrões para a heurística construtiva gulosa acima. Sem perda de generalidade, admitimos que a orientação dos itens é fixada, isto é, os comprimentos $l_{i}$ dos itens devem estar sempre paralelos ao comprimento $L$ da chapa. Caso contrário, basta considerarmos cada tipo de item $\left(l_{i}, w_{i}\right)$ como dois tipos com dimensões $\left(l_{i}, w_{i}\right)$ e $\left(w_{i}, l_{i}\right)$. Sejam $X$ e $Y$ os conjuntos das combinações lineares com coeficientes inteiros não negativos das dimensões dos itens ao longo do comprimento $L$ e da largura $W$ da chapa, 
respectivamente. Ou seja, sem perda de generalidade (Herz, 1972; Christofides \& Whitlock, 1977), os possíveis cortes a serem considerados ao longo de $L$ e $W$ podem ser reduzidos aos elementos dos conjuntos $X$ e $Y$ (incluindo $L$ e $W$ ):

$$
\begin{aligned}
& X=\left\{x_{1} \mid x_{1}=\sum_{i=1}^{m} \alpha_{i} l_{i}, x_{1} \leq L-l_{0}, \alpha_{i} \geq 0 \text { e inteiro }\right\} \cup\{L\}, l_{0}=\min _{i=1, \ldots, m}\left\{l_{i}\right\} \\
& Y=\left\{y_{1} \mid y_{1}=\sum_{i=1}^{m} \alpha_{i} w_{i}, y_{1} \leq W-w_{0}, \alpha_{i} \geq 0 \text { e inteiro }\right\} \cup\{W\}, w_{0}=\min _{i=1, \ldots, m}\left\{w_{i}\right\}
\end{aligned}
$$

Os conjuntos $X$ e $Y$ podem ser gerados da seguinte maneira (Morabito, 1992): seja $f\left(x_{1}\right)$ uma função Booleana com valor verdade, se $x_{1} \in X$, e valor falso, caso contrário. Tem-se inicialmente que $f\left(x_{1}\right)=$ verdade para $x_{1}=l_{i}, i=1, \ldots, m$ e $f\left(x_{1}\right)=$ falso para $x_{1}<l_{0}$. Cada um dos demais valores de $f\left(x_{1}\right), l_{0}+1 \leq x_{1} \leq L-l_{0}$, é verdade se ao menos um dos valores em $\left\{f\left(x_{1}-l_{i}\right), i=1, \ldots, m\right\}$ for verdade. O mesmo procedimento pode ser aplicado para o conjunto $Y$ definindo-se uma função Booleana $f\left(y_{1}\right)$.

Sejam as fórmulas recursivas $f^{t}(x, W)$ e $f^{l}(L, y), x \in X$ e $y \in Y$, definidas como:

$$
\begin{aligned}
& \left.f^{t}(x, W)=\max \left\{\begin{array}{l}
\left.f^{t} \text { (predecessor }(x), W\right), \\
f^{m y}(W)=\left\{\begin{array}{l}
\max \left\{\sum_{\left\{i \mid l_{i}=x\right\}} v_{i} a_{i}, \sum_{\left\{i l_{i}=x\right\}} w_{i} a_{i} \leq W, a_{i} \geq 0 \text { e inteiro }\right\}, \\
\text { se } x \leq 2200 \\
0, \text { caso contrário. }
\end{array}\right. \\
\max _{i=1, \ldots, m}\left\{v_{i}\left\lfloor x / l_{i}\right\rfloor\left\lfloor W / w_{i}\right\rfloor, l_{i} \leq 2200\right\} .
\end{array}\right\},\right\} \\
& f^{l}(x, y)=\max \left\{\begin{array}{l}
f^{l}(x, \text { predecessor }(y)), \\
f^{m x}(x)=\max \left\{\sum_{\left\{i \mid w_{i}=y\right\}} v_{i} a_{i}, \sum_{\left\{i \mid w_{i}=y\right\}} l_{i} a_{i} \leq x, a_{i} \geq 0 \text { e inteiro }\right\} .
\end{array}\right\}
\end{aligned}
$$

onde $f^{t}(x, W)=0$ se $x=0$, e $f^{l}(x, y)=0$ se $x=0$ ou $y=0$ (a notação $\lfloor x\rfloor$ representa o maior inteiro menor ou igual a $x$ ).

A função $f^{t}(x, W)$ corresponde ao valor do padrão mais valioso com cortes guilhotinados transversais (i.e., paralelos a $W$ ) na faixa $(x, W)$. Este valor é igual ao maior valor entre: (i) $f^{t}$ (predecessor $\left.(x), W\right)$, o valor do padrão mais valioso com cortes guilhotinados transversais na faixa (predecessor $(x), W)$, onde $\operatorname{predecessor}(x)=\max \left\{x_{1} \in X \mid x_{1}<x\right\}$ representa o maior comprimento em $X$ menor que $x$, (ii) $f^{m y}(W)$, o valor da solução de um problema da mochila unidimensional em $W$ na faixa $(x, W)$ (somente com itens com comprimento $l_{i}=x$ ), se $x \leq 2200 \mathrm{~mm}$ (Figura 8 (a)), (iii) o valor de melhor solução homogênea na faixa $(x, W)$ (i.e., composta de itens do mesmo tipo $i$ tal que $l_{i} \leq 2200 \mathrm{~mm}$ ) (Figura 8 (b)). As restrições $x \leq 2200 \mathrm{em}$ (ii) e $l_{i} \leq 2200 \mathrm{em}$ (iii) referem-se ao comprimento de corte máximo da serra transversal (seção 2). Assim, os itens no padrão representado por $f^{t}(x, W)$ devem possuir comprimentos $l_{i}$ menores que $2200 \mathrm{~mm}$, caso contrário não poderiam ser cortados na serra transversal. 


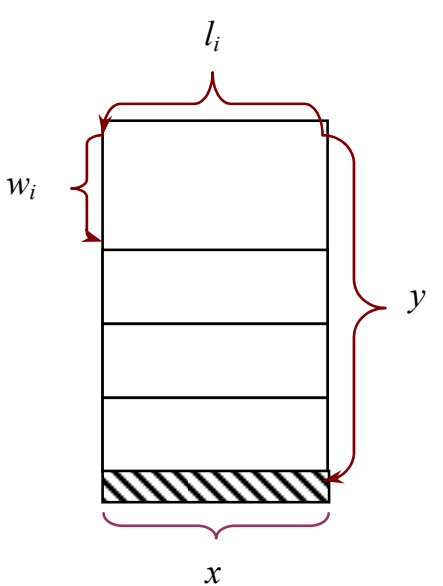

(a)

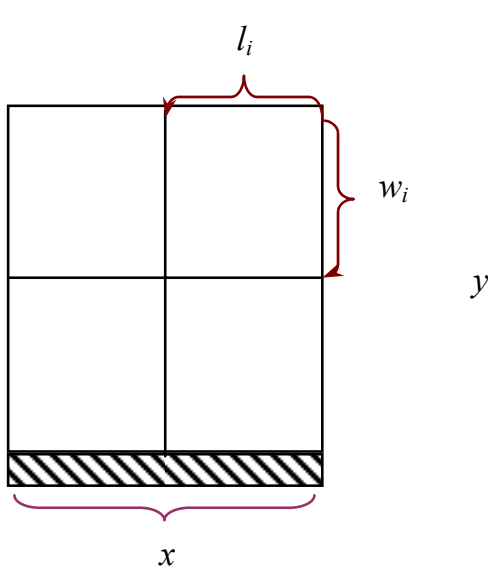

(b)

Figura 8 - (a) Solução da mochila unidimensional em $y$ na faixa $(x, y)$ (somente com itens com comprimentos $l_{i}=x$ ); (b) solução homogênea na faixa $(x, y)$.

Similarmente, $f^{l}(x, y)$ corresponde ao padrão mais valioso com cortes guilhotinados longitudinais (i.e., paralelos a $x$ ) na faixa $(x, y)$. Este valor é igual ao maior valor entre: (i) $f^{l}(x$, predecessor $(y))$, o valor do padrão mais valioso com cortes guilhotinados longitudinais na faixa (x,predecessor $(y))$, onde predecessor $(y)=\max \left\{y_{1} \in Y \mid y_{1}<y\right\}$ representa a maior largura em $Y$ menor que $y$, (ii) $f^{m x}(x)$, o valor da solução de um problema da mochila unidimensional em $x$ na faixa $(x, y)$ (somente com itens com largura $w_{i}=y$ ).

Os problemas da mochila unidimensionais em (6) e (7) podem ser resolvidos por programação dinâmica (Martello \& Toth, 1990). Seja $f_{i}^{m y}(y)$ o máximo valor obtido ao combinar-se as larguras $w_{1}, w_{2}, \ldots, w_{i}, i=1,2, \ldots, m$, ao longo da largura $y$. Cada $f_{i}^{m y}(y)$ é definido por: $f_{i}^{m y}(y)=\max \left\{f_{i-1}^{m y}(y), v_{i}+f_{i}^{m y}\left(y-w_{i}\right)\right\}, i=1,2, \ldots, m$, onde $f_{0}^{m y}(y)=0$. Logo, $f^{m y}(W)=f_{m}^{m y}(W)$ em (6). Similarmente para $f_{i}^{m x}(x)$ e $f^{m x}(x)=f_{m}^{m x}(x)$ em (7).

O melhor padrão guilhotinado 2-estágios para $(x, y)$ pode ser determinado em função de $f^{l}(x, y)$ em (7), pela seguinte fórmula recursiva $g(x, y)$ para $x \in X$ e $y \in Y$ :

$$
g(x, y)=\max _{0<y_{1} \leq \min \{y, 2200\}, y_{1} \in Y}\left\{f^{l}\left(x, y_{1}\right)+g\left(x,\left\lfloor y-y_{1}\right\rfloor_{y}\right\}\right.
$$

onde $g(x, y)=0$ se $x=0$ ou $y=0$, e $\lfloor y\rfloor_{y}=\max \left\{y_{1} \in Y \mid y_{1} \leq y\right\}$. Note em (8) que o padrão ótimo 2-estágios para $(x, y)$ combina o padrão mais valioso com cortes guilhotinados longitudinais (i.e., paralelos a $x$ ) na faixa $\left(x, y_{1}\right)$, com o padrão 2-estágios mais valioso na faixa restante $\left(x, y-y_{1}\right)$ (Figura 9). 


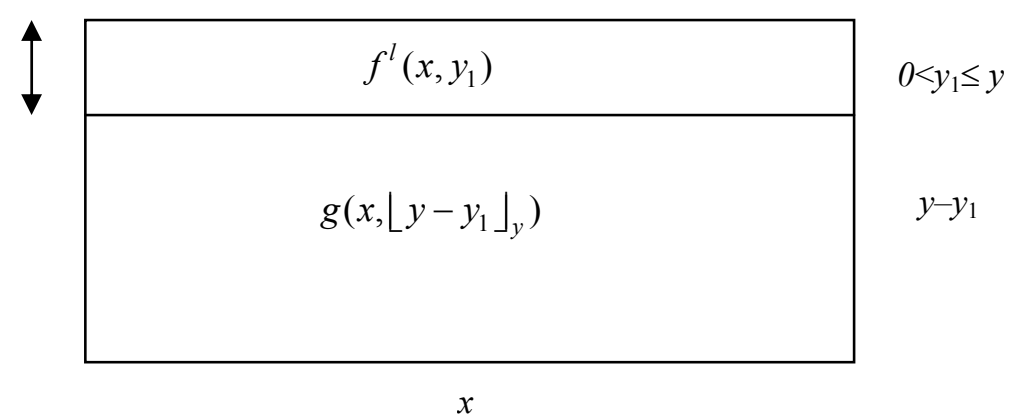

Figura 9 - Padrão guilhotinado 2-estágios para $(x, y)$.

O melhor padrão com até $k$ cortes de cabeça para $(x, W)$ pode ser determinado em função de $f^{t}(x, W)$ em (6), pela seguinte fórmula recursiva $f_{k}(x, W)$ para $x \in X, x \leq L-20 \mathrm{~mm}$ :

$$
\begin{aligned}
& f_{k}(x, W)=\max _{0<x_{1} \leq x-1000, x_{1} \in X}\left\{f_{k-1}(x, W), f^{t}\left(x_{1}, W\right)+f_{k-1}\left(\left\lfloor x-x_{1}\right\rfloor_{x}, W\right)\right\}, k=1, \ldots, 5 \\
& f_{0}(x, W)=g(x, W)
\end{aligned}
$$

onde $f_{k}(x, W)=0$ se $x=0$, e $\lfloor x\rfloor_{x}=\max \left\{x_{1} \in X \mid x_{1} \leq x\right\}$. O $k$-ésimo corte $x_{1}$ corresponde ao primeiro corte de cabeça. O limite $k \leq 5$ refere-se ao número máximo de cortes de cabeça que o equipamento pode fazer (seção 2). A restrição $x-x_{1} \geq 1000 \mathrm{~mm}$ é a condição necessária para que o pacote principal (parte da chapa depois de retiradas as cabeças) consiga completar o giro com segurança (seção 2). Note em (9) que o padrão ótimo com até $k$ cortes de cabeça para $(x, W)$ combina o padrão mais valioso com cortes guilhotinados transversais (i.e., paralelos a $W$ ) na faixa $\left(x_{1}, W\right)$, com o padrão mais valioso com até $k$-1 cortes de cabeça na faixa restante $\left(x-x_{1}, W\right)$ (Figura 10). Se $k=0$ (nenhum corte de cabeça), a função $f_{0}(x, W)$ é igual a $g(x, y)$. Se $k=1$, a função $f_{1}(x, W)$ avalia se $f_{0}(x, W)$ (nenhum corte de cabeça) é melhor que $f^{t}\left(x_{1}, W\right)+f_{0}\left(\left\lfloor x-x_{1}\right\rfloor_{x}, W\right)$ (um corte de cabeça na posição $x_{1}$ ). E assim por diante se $k=2, \ldots, 5$, ou seja, com dois, ..., cinco cortes de cabeça.

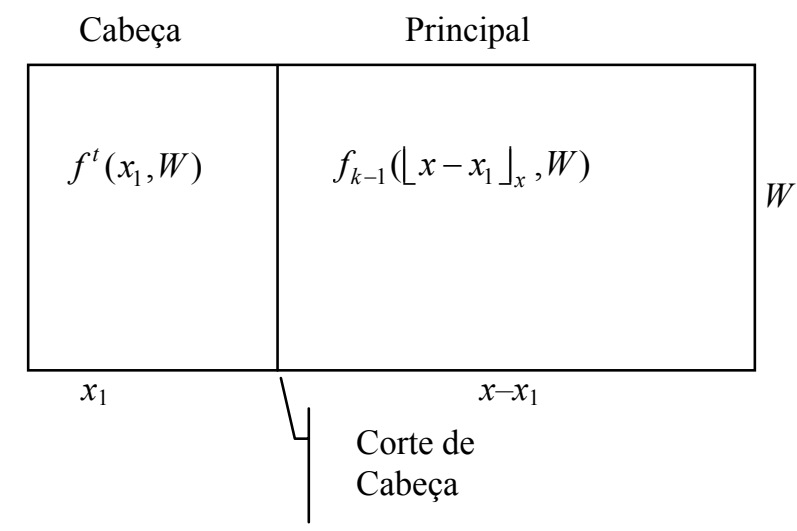

Figura 10 - Padrão com até $k$ cortes de cabeça para $(x, W)$. 
Note em (9) que $f_{k}(L, W)$ foi definida para $x \leq L-20 \mathrm{~mm}$. Para $x=L$, devemos considerar a restrição do pré-corte (veja retrim na seção 2), ou seja, feito um corte de cabeça, a serra, ao retornar o giro, executa um corte de $20 \mathrm{~mm}$ para ajustes de posicionamento das garras (Figura 11). Assim, completamos a definição de $f_{k}(L, W)$ para $x=L$ com:

$$
\begin{aligned}
f_{k}(L, W)= & \max _{0<x_{1} \leq L-1000-20, x_{1} \in X}\left\{f_{k-1}(L, W), f^{t}\left(x_{1}, W\right)+f_{k-1}\left(\left\lfloor L-x_{1}-20\right\rfloor_{x}, W\right)\right\}, \\
& k=1, \ldots, 5
\end{aligned}
$$

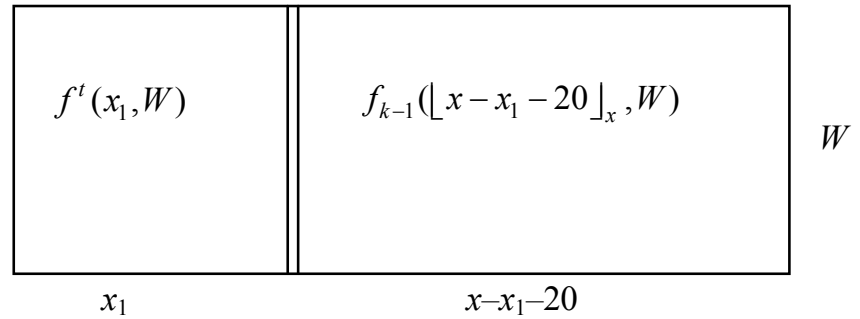

Figura 11 - Padrão com até $k$ cortes de cabeça e retrim de $20 \mathrm{~mm}$ para $(L, W)$.

As fórmulas $f^{t}(x, W)$ e $f^{l}(x, y)$ em (6) e (7) não consideram a restrição do número máximo de 4 tipos de itens no padrão (devido à limitação do número de estações de descarregamento automáticas da serra; veja seção 2). Uma simples maneira de considerar esta restrição na heurística gulosa (com perda de generalidade) é redefinir o Passo 1 como:

Passo 1:

Passo 1.1: Seja $M=\{1,2,3, . ., m\}$ a lista contendo todos os tipos de itens.

Passo 1.2: Gere o melhor padrão para os itens da lista $M$.

Passo 1.3: Se o padrão for factível (i.e, o máximo número de tipos de itens é menor ou igual 4), pare. Caso contrário, retire aleatoriamente da lista $M$ um dos tipos de itens do padrão (por exemplo, o de menor demanda), e volte para o Passo 1.2.

Observe que com esta modificação, o subproblema (P1) pode ter que ser resolvido mais de uma vez em cada iteração da heurística gulosa. Um procedimento similar ao acima também pode ser definido no algoritmo simplex com geração de padrões, ao se resolver o subproblema (P1). Neste caso tal subproblema pode ter que ser resolvido mais de uma vez em cada iteração simplex. Note que em ambos os casos estamos perdendo generalidade. Conforme discutido na seção 2, esta restrição do número máximo de 4 tipos de itens no padrão pode ser relaxada ao se utilizar a estação de descarregamento manual da serra para descarregar os itens que não foram alocados nas estações automáticas.

Convém salientar que as fórmulas recursivas de programação dinâmica apresentadas nesta seção não consideram a restrição de demanda $b_{i}$ na geração do padrão, ou seja, caso $b_{i}$ seja bem pequeno (i.e., menor que $\left\lfloor L / l_{i}\right\rfloor\left\lfloor W / w_{i}\right\rfloor$ ), elas podem gerar um padrão contendo uma quantidade de itens do tipo $i$ maior que $b_{i}$. Esta restrição é menos importante na prática das fábricas de chapas duras, uma vez que as demandas dos itens são relativamente grandes. A extensão destas fórmulas para considerar tal restrição não é trivial. 


\section{Resultados Computacionais}

Nesta seção, para ilustrar a viabilidade do uso do algoritmo de programação dinâmica (9)-(10) para gerar padrões de corte de chapas duras (i.e., resolver o subproblema (P1)), apresentamos os resultados computacionais das duas abordagens acima: abordagem 1 (heurística gulosa com gerador de padrões) e abordagem 2 (algoritmo simplex com gerador de padrões) para resolver um exemplo real fornecido pela empresa. Comparamos os resultados das abordagens 1 e 2 com os utilizados pela empresa, obtidos pelo software da serra Holzma. Também analisamos isoladamente o desempenho computacional do algoritmo de programação dinâmica em 100 exemplos gerados aleatoriamente.

A Tabela 4 apresenta os dados da carteira de pedidos, com as dimensões das chapas (todas iguais) e dos $m=12$ tipos de itens. Conforme discutido na seção 2, adicionamos a espessura de $6 \mathrm{~mm}$ das serras longitudinais e transversais nas dimensões das chapas $(L, W)$ e dos itens $\left(l_{i}, w_{i}\right)$. No entanto, os valores $v_{i}$ dos itens foram considerados iguais às suas áreas originais, $\mathrm{e}$ não às suas áreas obtidas com as dimensões acrescidas da espessura da serra. A coluna "Área" da tabela refere-se aos valores $v_{i}$ (áreas dos itens), calculados com os comprimentos e larguras originais, e a coluna "Demanda" refere-se às demandas $b_{i}$. Como os itens não possuem orientação fixa, sem perda de generalidade consideramos apenas no gerador de padrões cada item $i$ como dois itens diferentes com dimensões $\left(l_{i}, w_{i}\right)$ e $\left(w_{i}, l_{i}\right)$. Para as chapas, descontamos os remates para aparar suas bordas $(17 \mathrm{~mm}$ em cada lado das larguras e $20 \mathrm{~mm}$ em cada lado dos comprimentos das chapas). Assim, o comprimento original das chapas reduziu de $4880 \mathrm{~mm}$ para $4846 \mathrm{~mm}$ (40 $\mathrm{mm}$ a menos de remates dos dois lados, mais $6 \mathrm{~mm}$ da espessura da serra), e largura original de $2170 \mathrm{~mm}$ para $2142 \mathrm{~mm}$ (34 $\mathrm{mm}$ a menos de remates, mais $6 \mathrm{~mm}$ de espessura da serra).

Tabela 4 - Dados da carteira de pedidos fornecida pela empresa.

\begin{tabular}{c|cccccc}
\hline $\begin{array}{c}\text { Chapa, } \\
\text { itens } i\end{array}$ & $\begin{array}{c}\text { Comprimento } \\
\text { original }\end{array}$ & $\begin{array}{c}\text { Largura } \\
\text { original }\end{array}$ & $\begin{array}{c}\text { Área } \\
v_{i} \\
\left(\mathrm{~mm}^{2}\right)\end{array}$ & $\begin{array}{c}\text { Comprimento } \\
\text { L, } l_{i} \\
(\mathrm{~mm})\end{array}$ & $\begin{array}{c}\text { Largura } \\
\text { W, } w_{i} \\
(\mathrm{~mm})\end{array}$ & $\begin{array}{c}\text { Demanda } \\
b_{i}\end{array}$ \\
\hline Chapa & 4880 & 2170 & 10.589 .600 & 4846 & 2142 & \\
1 & 864 & 762 & 658.368 & 870 & 768 & 3000 \\
2 & 1067 & 919 & 980.573 & 1073 & 925 & 1500 \\
3 & 2032 & 1219 & 2.477 .008 & 2038 & 1225 & 10000 \\
4 & 1220 & 919 & 1.121 .180 & 1226 & 925 & 4000 \\
5 & 1575 & 762 & 1.200 .150 & 1581 & 768 & 4000 \\
6 & 1955 & 765 & 1.495 .575 & 1961 & 771 & 750 \\
7 & 1245 & 370 & 460.650 & 1251 & 376 & 2250 \\
8 & 1245 & 235 & 292.575 & 1251 & 241 & 2500 \\
9 & 1200 & 465 & 558.000 & 1206 & 471 & 1000 \\
10 & 1200 & 725 & 870.000 & 1206 & 731 & 1000 \\
11 & 1105 & 465 & 513.825 & 1111 & 471 & 500 \\
12 & 2130 & 1375 & 2.928 .750 & 2136 & 1381 & 2600 \\
\hline
\end{tabular}




\subsection{Abordagem 1 - Heurística gulosa com gerador de padrões}

A heurística gulosa e as fórmulas recursivas de programação dinâmica da seção 3 foram implementadas na linguagem Pascal num microcomputador Pentium III com $256 \mathrm{Mb}$ e 350 Mhz. Os resultados a seguir foram obtidos usando todos os elementos de discretização dos conjuntos $X$ e $Y$ em (4) e (5), ou seja, 2896 e 313 elementos, respectivamente. As mochilas unidimensionais em (6) e (7) também foram resolvidas por programação dinâmica, conforme discussão na seção 3 .

A Tabela 5 compara as demandas dos itens com as quantidades geradas pelas soluções da empresa e da abordagem 1 (com no máximo 5 cortes de cabeça e no máximo 4 tipos de itens no padrão). A solução da empresa foi gerada pelo software da serra com o objetivo de minimizar a perda de material, mas levando em conta o seqüenciamento de padrões. Observe que as demandas de todos os itens foram atendidas nas duas soluções, sendo que a solução da empresa produz 413 itens além da demanda, enquanto a solução da abordagem 1 produz apenas 14 itens. A quantidade cortada de cada padrão e a perda percentual (que inclui o resto de material mais o material consumido pela espessura da serra) estão apresentadas na Tabela 6. Na solução da abordagem 1 , foram necessárias 5418 chapas $\left(57374 \mathrm{~m}^{2}\right)$, enquanto na solução da empresa foram 5516 chapas $\left(58412 \mathrm{~m}^{2}\right)$, resultando em um adicional de 1038 $\mathrm{m}^{2}$ (Tabela 6). Ambas as soluções utilizam 11 padrões de corte diferentes. Se considerarmos o excesso de itens como estoque de itens, as soluções da abordagem 1 e da empresa resultam em perdas percentuais de $13,37 \%$ e $13,21 \%$, respectivamente. Se considerarmos este excesso simplesmente como perda de material, estes valores resultam em 13,39\% e 14,93\%. Como a solução da empresa considera que, em períodos de alta demanda, o excesso de certos itens em geral não resulta num problema maior porque estes itens permanecem pouco tempo em estoque, a comparação direta entre as duas soluções deve ser feita com cautela.

Tabela 5 - Quantidades de itens produzidos pelas soluções da empresa e abordagem 1.

\begin{tabular}{c|ccccc}
\hline $\begin{array}{c}\text { Chapa, } \\
\text { item } i\end{array}$ & $\begin{array}{c}\text { Comprimento } \\
L, l_{i}\end{array}$ & $\begin{array}{c}\text { Largura } \\
W, w_{i}\end{array}$ & $\begin{array}{c}\text { Demanda } \\
b_{i}\end{array}$ & $\begin{array}{c}\text { Produção } \\
\text { empresa }\end{array}$ & $\begin{array}{c}\text { Produção } \\
\text { abordagem 1 }\end{array}$ \\
\hline Chapa & 4880 & 2170 & & & \\
1 & 864 & 762 & 3000 & 3000 & 3005 \\
2 & 1067 & 919 & 1500 & 1500 & 1500 \\
3 & 2032 & 1219 & 10000 & 10400 & 10002 \\
4 & 1220 & 919 & 4000 & 4004 & 4000 \\
5 & 1575 & 762 & 4000 & 4001 & 4002 \\
6 & 1955 & 765 & 750 & 750 & 750 \\
7 & 1245 & 370 & 2250 & 2256 & 2255 \\
8 & 1245 & 235 & 2500 & 2500 & 2500 \\
9 & 1200 & 465 & 1000 & 1000 & 1000 \\
10 & 1200 & 725 & 1000 & 1000 & 1000 \\
11 & 1105 & 465 & 500 & 501 & 500 \\
12 & 2130 & 1375 & 2600 & 2601 & 2600 \\
Total & & & 33100 & 33513 & 33114 \\
\hline
\end{tabular}


Tabela 6 - Quantidades produzidas e perdas percentuais dos padrões da empresa e abordagem 1.

\begin{tabular}{c|cccc}
\hline Padrão $j$ & \multicolumn{2}{|c}{ Empresa } & \multicolumn{2}{c}{ Abordagem 1 } \\
\hline & $\begin{array}{c}\text { Número de } \\
\text { vezes } x_{j}\end{array}$ & $\begin{array}{c}\text { Perda } \\
(\%)\end{array}$ & Número de & Pezes $x_{j}$ \\
1 & 650 & 7,17 & 205 & $(\%)$ \\
2 & 750 & 11,31 & 250 & 5,87 \\
3 & 100 & 12,94 & 90 & 5,04 \\
4 & 2400 & 15,73 & 660 & 6,16 \\
5 & 250 & 12,06 & 550 & 7,17 \\
6 & 167 & 9,15 & 100 & 8,86 \\
7 & 567 & 12,18 & 215 & 9,11 \\
8 & 39 & 13,06 & 575 & 9,76 \\
9 & 333 & 9,76 & 397 & 11,31 \\
10 & 202 & 20,96 & 2289 & 13,06 \\
11 & 58 & 21,70 & 87 & 32,49 \\
Total & 5516 & 13,21 & 5418 & 13,37 \\
Total s/ Estoques & & 14,93 & & 13,39 \\
\hline
\end{tabular}

Além disso, é importante destacar que a abordagem 1, diferente do software da empresa, não considera a restrição dos alimentadores de paletes das estações automáticas. Lembre-se da discussão da seção 2 que isto implica que, enquanto o palete não estiver completo de um tipo de item, a estação não pode descarregar outro tipo de item. Portanto, dada uma seqüência de padrões de corte, o número máximo de pilhas de itens abertas (ao longo desta seqüência) deve ser no máximo igual a 4. Examinando todas as $m$ ! possíveis seqüências de padrões, verificamos que, para este exemplo, os padrões produzidos pela abordagem 1 são seqüenciáveis com 5 pilhas abertas. Ou seja, se os alimentadores de paletes das estações automáticas estiverem operando, é necessário utilizar-se a estação de descarregamento manual.

Como a abordagem 1 utiliza uma heurística gulosa, espera-se que o primeiro padrão gerado seja tão bom ou melhor do que o segundo, que por sua vez seja tão bom ou melhor do que o terceiro, e assim por diante. No entanto, note na Tabela 6 que a perda do primeiro padrão da abordagem 1 é um pouco maior do que a do segundo, o que não era esperado. Isso ocorre devido ao procedimento de factibilização dos padrões no passo 1 da heurística gulosa (seção 3), que retira arbitrariamente o item de menor demanda dentre os itens num padrão infactível (com mais de 4 tipos de itens). Neste exemplo, em particular, o item retirado na primeira iteração deste procedimento possuía dimensões convenientes para minimizar a perda do padrão. À medida que os próximos padrões vão sendo gerados pela abordagem 1, algumas das demandas se anulam e portanto, o número de itens a considerar decresce, diminuindo as possibilidades de combinações possíveis. Com isso, os padrões tendem a ter perdas cada vez maiores. Mesmo assim, conforme comentado acima, as diferenças entre as perdas percentuais encontradas pela empresa e pela abordagem 1 são pouco expressivas, com um menor número de chapas cortado pela abordagem 1 (Tabela 6).

Realizamos mais dois experimentos com a abordagem 1 e a carteira de pedidos da Tabela 4 . No primeiro experimento, eliminamos a possibilidade dos cortes de cabeça nos padrões (ou seja, fixamos $k=0$ em (9)-(10)), para avaliarmos as perdas sem estes cortes (mantendo a 
restrição de no máximo 4 tipos de itens no padrão). Os resultados obtidos encontram-se na Tabela 7; as colunas apresentam o número de vezes que cada padrão é produzido e a perda percentual de cada padrão. No segundo experimento, alteramos a restrição de no máximo 4 tipos de itens no padrão para no máximo 5 tipos de itens, para avaliarmos as perdas com a limitação das 4 estações de descarregamento automáticas. Nesta solução, o quinto tipo de item teria de ser empacotado manualmente na estação de descarregamento manual da serra. Os resultados obtidos também se encontram na Tabela 7. Para mais detalhes dos padrões gerados nestas duas soluções, o leitor pode consultar Belluzzo (2002).

Tabela 7 - Comparação dos padrões gerados pela abordagem 1 com restrições de: (i) sem a possibilidade de giro $(k=0)$, e (ii) no máximo 5 tipos de itens por padrão.

\begin{tabular}{c|cccc}
\hline \multirow{2}{*}{ Padrão $j$} & \multicolumn{2}{|c}{$\begin{array}{c}\text { Abordagem } 1 \\
\text { (sem giro: } k=0)\end{array}$} & \multicolumn{2}{c}{$\begin{array}{c}\text { Abordagem 1 } \\
\text { (max 5 tipos }\end{array}$} \\
\hline & $\begin{array}{c}\text { Número de }) \\
\text { vezes } x_{j}\end{array}$ & $\begin{array}{c}\text { Perda } \\
(\%)\end{array}$ & $\begin{array}{c}\text { Número de } \\
\text { vezes } x_{j}\end{array}$ & $\begin{array}{c}\text { Perda } \\
(\%)\end{array}$ \\
1 & 250 & 5,04 & 334 & 4,66 \\
2 & 250 & 6,97 & 53 & 5,87 \\
3 & 50 & 7,44 & 328 & 6,16 \\
4 & 125 & 9,29 & 100 & 6,28 \\
5 & 75 & 9,76 & 422 & 7,17 \\
6 & 209 & 12,68 & 383 & 8,86 \\
7 & 450 & 13,06 & 100 & 9,11 \\
8 & 125 & 15,26 & 346 & 9,76 \\
9 & 867 & 17,03 & 316 & 11,31 \\
10 & 759 & 19,22 & 309 & 13,06 \\
11 & 2.828 & 29,83 & 2.683 & 18,49 \\
12 & & & 65 & 32,00 \\
Total & 5.988 & 21,61 & 5.439 & 13,70 \\
Total s/ Estoques & & 21,64 & & 13,73 \\
\hline
\end{tabular}

Note na Tabela 7 que, para este exemplo, a solução da abordagem 1 usando a estação de descarregamento manual é um pouco pior do que a solução usando apenas as estações automáticas. Este resultado não era esperado, uma vez que o problema fica menos restrito. Isso ocorre devido ao procedimento de factibilização dos padrões no passo 1 da heurística gulosa, que retira arbitrariamente o item de menor demanda dentre os itens num padrão infactível (com mais de 4 tipos de itens). Por exemplo, note no padrão 1 da Tabela 7 que o item retirado para factibilizar o padrão com no máximo 4 tipos de itens era um item com dimensões apropriadas para gerar uma solução com baixo índice de perda. Isto resultou numa solução um pouco pior do que a solução sem possibilidade de giro do pacote $(5,87 \%$ contra $5,04 \%)$.

Observe na Tabela 7 que os padrões gerados pela abordagem 1 com no máximo 5 tipos de itens possuem perda menor do que os padrões com no máximo 4 tipos de itens e impossibilidade de giro do pacote. A única exceção ocorre no padrão 2. Mesmo assim, a perda total (considerando excesso de itens como estoque) com no máximo 5 tipos de itens 
(13,70\%) é maior do que a de no máximo 4 tipos de itens por padrão (13,37\%), e utiliza 21 chapas a mais. Com relação aos padrões sem possibilidade de giro, observa-se um aumento significativo na perda de cada padrão e na perda total $(21,61 \%)$. Estas observações também são válidas considerando excesso de itens como perda de material.

A perda acumulada mostra que a abordagem 1 produz padrões com perdas baixas no início das iterações, mas à medida que a carteira (admitida fixa) vai se exaurindo, os padrões têm perdas cada vez maiores. Em ambientes dinâmicos onde novos pedidos eventualmente entram na carteira, espera-se que o desempenho da abordagem 1 não piore tanto nos últimos padrões. Neste caso, políticas de priorização de itens baseadas nos prazos de entrega também podem ser incorporadas na abordagem, modificando-se os valores dos itens (similarmente à discussão em Silva \& Morabito, 2004).

\subsection{Abordagem 2 - Algoritmo simplex com gerador de padrões}

A seguir comparamos as soluções da empresa e da abordagem 1 com as da abordagem 2. Para isto, utilizamos a implementação computacional de Morabito \& Garcia (1998a). Nesta implementação, substituímos o algoritmo de geração de colunas descrito em Morabito \& Garcia (1998a) pelo presente algoritmo de programação dinâmica (seção 3). As implementações também foram feitas em linguagem Pascal e foi utilizado o mesmo microcomputador especificado da seção 4.1.

A Tabela 8 resume os resultados obtidos após o simples arredondamento para cima da solução relaxada de (P), considerando o excesso de itens como estoque de itens. A coluna $|X|$, $|Y|$ apresenta o número máximo de elementos permitidos nos conjuntos $X$ e $Y$ (esta limitação é aplicada utilizando-se um procedimento heurístico descrito em Morabito \& Garcia, 1998a). Dependendo do problema, tal limitação é necessária devido aos requisitos de memória computacional da nossa implementação. As demais colunas representam o máximo de cortes de cabeça permitidos $(k)$, o máximo número de tipos de itens no padrão $(p)$, a perda total percentual e em $\mathrm{m}^{2}$, o número de chapas utilizadas, o número de iterações executado pelo método simplex e a quantidade de padrões gerados.

Tabela 8 - Resultados obtidos com a abordagem 2: o algoritmo de programação dinâmica incorporado no algoritmo simplex com geração de colunas de Morabito \& Garcia (1998a).

\begin{tabular}{c|cccccccc}
\hline $\begin{array}{c}\text { Número cortes } \\
\text { cabeça } k\end{array}$ & $\begin{array}{c}\text { Número tipos } \\
\text { itens } p\end{array}$ & $|X|,|Y| \begin{array}{c}\text { Perda } \\
(\%)\end{array}$ & $\begin{array}{c}\text { Perda } \\
\left(\mathrm{m}^{2}\right)\end{array}$ & $\begin{array}{c}\text { Número } \\
\text { chapas }\end{array}$ & $\begin{array}{c}\text { Número } \\
\text { iteraçóes }\end{array}$ & $\begin{array}{c}\text { Número } \\
\text { padrões }\end{array}$ & Obs. \\
\hline 5 & 4 & 200 & 11,90 & $6.710,60$ & 5456 & 40 & 11 \\
5 & 4 & 500 & 8,04 & $4.342,40$ & 5226 & 33 & 12 \\
5 & 4 & 1000 & 8,04 & $4.342,40$ & 5226 & 43 & 12 \\
5 & 4 & 1500 & 8,04 & $4.342,40$ & 5226 & 43 & 12 & \\
5 & 4 & 3000 & 7,96 & $4.298,70$ & 5223 & 35 & 12 & $(1)$ \\
5 & 5 & 1000 & 8,04 & $4.342,40$ & 5226 & 39 & 12 & \\
5 & 5 & 2000 & 8,04 & $4.342,40$ & 5226 & 39 & 12 & \\
5 & 5 & 3000 & 7,96 & $4.298,70$ & 5223 & 35 & 12 & $(2)$ \\
0 & 4 & 3000 & 18,58 & $11.340,40$ & 5903 & 22 & 12 & \\
\hline
\end{tabular}

(1) A solução utiliza padrões com 4 tipos de itens;

(2) A solução não utiliza padrões com 5 tipos de itens 
Para que todos os elementos de $X$ e $Y$ sejam gerados, necessitamos de 2896 pontos de discretizações. Nestes casos (linhas com $k=5, p=4$ e $|X|=3000$, e $k=5, p=5$ e $|X|=3000$ da Tabela 8), o programa computacional consome ordem de dezenas de minutos ou horas para obter uma solução no microcomputador Pentium III. Assim como a abordagem 1, a abordagem 2 também não considera a restrição dos alimentadores de paletes das estações automáticas, ou seja, o número máximo de pilhas de itens abertas (ao longo da seqüência de padrões de corte) deve ser no máximo igual a 4, uma pilha para cada estação automática. Esta restrição é válida somente se os alimentadores de paletes estiverem operando, ou a estação manual não estiver operando.

Os resultados para $k=5$ e padrões com no máximo 4 tipos de itens, obtidos pela abordagem 2, foram melhores $(7,96 \%$ de perda utilizando 5223 chapas; Tabela 8$)$ do que os encontrados pela abordagem $1(13,37 \%$ de perda utilizando 5418 chapas; Tabela 6) e pela empresa (13,21\% de perda utilizando 5516 chapas; Tabela 6). Ou seja, a abordagem 2 encontra uma solução com 5,41\% a menos de perda do que a abordagem 1, consumindo 195 chapas a menos (resultados similares são obtidos considerando o excesso de itens como perda de material). Por outro lado, o tempo computacional gasto pela abordagem 2 é bem maior (ordem de dezenas de minutos ou horas) do que o da abordagem 1 (ordem de dezenas de segundos ou poucos minutos). Examinando todas as $m$ ! possíveis seqüências de padrões da solução da abordagem 2, verificamos que estes padrões são seqüenciáveis com 5 pilhas abertas (similarmente à solução da abordagem 1). Ou seja, se os alimentadores de paletes das estações automáticas estiverem operando, também é necessário utilizar-se a estação de descarregamento manual.

As abordagens 1 e 2 mostram a necessidade de se estudar melhor a relação entre o giro do pacote e a perda de material, pois as diferenças encontradas para este exemplo são significativas em termos de perdas e, conseqüentemente, custos de produção. A incorporação de mais um tipo de item no padrão não gerou diferenças significativas para este exemplo, o que pode não acontecer em outros exemplos. Na abordagem 1, a solução com no máximo 5 tipos de itens no padrão resultou numa perda maior do que a solução com no máximo 4 tipos de itens. Na abordagem 2, a solução encontrada não utilizou, mesmo que permitido, padrões com 5 tipos de itens. Convém salientar que estas observações são baseadas em apenas um exemplo fornecido pela empresa, o que é pouco conclusivo. Por outro lado, a análise de outros exemplos ficou prejudicada devido a dificuldades encontradas para se obter outras carteiras de pedidos na empresa.

\subsection{Experimentos com gerador de padrões}

Para avaliar melhor o desempenho computacional do algoritmo de programação dinâmica para gerar padrões de mínima perda factíveis para a serra Holzma, realizamos mais um experimento com 5 conjuntos de exemplos gerados aleatoriamente com dimensões das chapas $(L, W)=(4846,2142) \mathrm{mm}$. Cada conjunto contém 20 exemplos com $m=5,10,20,30$ e 50 tipos de itens, respectivamente, com dimensões $\left(l_{i}, w_{i}\right), i=1, \ldots, m$, sorteadas uniformemente nos intervalos $[0,15 \mathrm{~L}, 0,85 \mathrm{~L}]$ e $[0,15 \mathrm{~W}, 0,85 \mathrm{~W}]$. Desta maneira, procurou-se gerar exemplos razoavelmente representativos da fábrica de chapas duras.

A Tabela 9 resume os resultados computacionais médios obtidos para os 5 conjuntos (total de 100 exemplos). A coluna $m$ indica o número de tipos de itens de cada exemplo do conjunto, as colunas 'Solução' e 'Desvio padrão' apresentam a média e o desvio padrão do 
aproveitamento da área da chapa (em porcentagem), a coluna 'Número de itens' apresenta o número médio de itens arranjados no padrão, e a coluna 'Tempo' apresenta o tempo médio de execução (em segundos). Nestes experimentos utilizou-se todos os elementos dos conjuntos $X$ e $Y$. Note que, a medida que aumentamos $m$, o tempo para gerar um padrão cresce sensivelmente, no entanto, ainda é aceitável para apoiar as decisões de programação da produção do equipamento de corte.

Tabela 9 - Resultados computacionais dos 100 exemplos aleatórios com $(L, W)=(4846,2142)$ e $\left(l_{i}, w_{i}\right), i=1, \ldots, m$, sorteados uniformemente nos intervalos $[0,15 L, 0,85 \mathrm{~L}] \mathrm{e}[0,15 \mathrm{~W}, 0,85 \mathrm{~W}]$.

\begin{tabular}{c|ccccc}
\hline Conjunto & $m$ & Solução & Desvio padrão & Número de itens & Tempo (seg) \\
\hline 1 & 5 & 0,8287 & 0,0546 & 4,75 & $<0,01$ \\
2 & 10 & 0,8995 & 0,0430 & 6,65 & 0,02 \\
3 & 20 & 0,9504 & 0,0208 & 8,90 & 0,63 \\
4 & 30 & 0,9659 & 0,0099 & 9,85 & 39,14 \\
5 & 50 & 0,9796 & 0,0057 & 11,05 & 132,57 \\
\hline
\end{tabular}

\section{Conclusões e Perspectivas}

Neste artigo analisamos o problema de corte que aparece num estudo de caso de uma fábrica de chapas duras. Após serem produzidas, as chapas duras devem ser cortadas num equipamento programável com alto nível de automação, para atender uma carteira de pedidos. Devido à escala de produção deste equipamento, pequenos ganhos percentuais no aproveitamento das chapas duras pode resultar em economias substanciais para a fábrica. Apesar da literatura conter diversos trabalhos explorando problemas de corte, o presente problema envolve restrições especiais associadas aos cortes longitudinais e transversais da serra, aos cortes de cabeça, ao giro do pacote de chapas e às estações de descarregamento de itens, que inviabilizam a aplicação direta das abordagens conhecidas.

Apresentamos um algoritmo de programação dinâmica para gerar padrões de corte de perda mínima factíveis para o equipamento de corte. Para ilustrar a viabilidade do uso deste gerador de padrões, ele foi acoplado em duas abordagens conhecidas da literatura para resolver o problema de corte: a abordagem 1 é baseada numa heurística construtiva gulosa e a abordagem 2, no método primal simplex com geração de colunas. Com base num exemplo real fornecido pela empresa, ambas as abordagens foram capazes de produzir resultados competitivos em relação aos utilizados pela empresa, e são promissoras, particularmente a abordagem 2. Também analisamos o desempenho computacional do algoritmo de programação dinâmica em diversos exemplos aleatórios de geração de padrões de corte. Convém salientar que não temos conhecimento de outros trabalhos na literatura estudando o problema de geração de padrões de corte para processos de corte com restrições semelhantes. Os trabalhos em Yanasse et al. (1991) e Morabito \& Garcia (1998a, 1998b) também trataram do problema de corte nas indústrias de madeira e chapas duras, porém envolvendo outros equipamentos de corte com características e restrições diferentes.

A abordagem 1 é capaz de produzir padrões eficientes do ponto de vista da perda percentual, principalmente nas primeiras iterações (primeiros padrões). Por ser baseada numa heurística gulosa, a abordagem tende a produzir padrões menos eficientes à medida que a demanda de itens vai se exaurindo. Em situações de demanda dinâmica, quando itens de novos pedidos 
vão sendo incluídos na carteira, esta abordagem pode-se tornar bem apropriada. Entretanto, nestes casos é necessário definir-se algum procedimento para priorizar os itens com prazos de entrega mais curtos (e.g., ajustando-se de alguma maneira os valores dos itens ao longo das iterações da abordagem).

A abordagem 2 foi capaz de gerar uma solução com mais de $5 \%$ a menos de perda em relação à abordagem 1 e à solução da empresa (compare Tabelas 8 e 6), o que é significativo do ponto de vista técnico e econômico, embora tal solução não satisfaça as restrições dos alimentadores de paletes das estações automáticas, se eles estiverem operando. No entanto, esta redução na perda de material pode tornar economicamente viável o uso da estação manual na prática. Os experimentos com impossibilidade de giro do pacote de chapas mostraram a necessidade de se explorar melhor as relações entre produtividade do equipamento e complexidade dos padrões de corte. Para o exemplo real analisado, as perdas saltaram de 7,96\% para 18,58\% em relação à solução com no máximo 4 tipos de itens no padrão (Tabela 8).

Como o problema de corte é parte da programação da produção de chapas duras, a solução do problema produz um conjunto de padrões de corte que nem sempre pode ser cortado em qualquer seqüência. Por exemplo, outros critérios e restrições podem ser levados em conta no seqüenciamento destes padrões, além da restrição do número máximo de pilhas abertas, tais como prazos de entrega dos itens e estoques intermediários. Uma perspectiva interessante para pesquisa futura é incorporar nas abordagens as decisões de seqüenciamento dos padrões, por exemplo, com base nos estudos em Pileggi (2002), Pinto (2004) e Pileggi et al. (2005). Outra perspectiva que está na nossa agenda de pesquisa é melhorar o desempenho da abordagem 1.

\section{Agradecimentos}

Os autores agradecem aos três revisores anônimos e a Gisele F. Pileggi pelos úteis comentários e sugestões. Esta pesquisa foi apoiada pelo CNPq (processo 522973/95-7) e pela FAPESP (processos 9522-0 e 01/2972-2).

\section{Referências Bibliográficas}

(1) Arenales, M.; Morabito, R. \& Yanasse, H. (1999). Special issue: Cutting and packing problems. Pesquisa Operacional, 19(2), 109-284.

(2) Ashikaga, F.M. (2001). Um método frugal para o problema de minimização de pilhas abertas. Dissertação de Mestrado, ITA, São José dos Campos, SP, Brasil.

(3) Becceneri, J.; Yanasse, H. \& Soma, N. (2004). A method for solving the minimization of the maximum number of open stacks problem within a cutting process. Computers and Operations Research, 31, 2315-2332.

(4) Belluzzo, L. (2002). Otimização nos planos de corte de chapas de fibra de madeira reconstituída: Um estudo de caso na programação da produção da serra Holzma. Dissertação de Mestrado, Departamento de Engenharia de Produção, UFSCar, São Carlos, SP.

(5) Bischoff, E. \& Waescher, G. (1995). Special issue on cutting and packing problems. European Journal of the Operational Research, 84(3), 503-712. 
(6) Christofides, N. \& Whitlock, C. (1977). An algorithm for two-dimensional cutting problems. Operations Research, 25(1), 30-44.

(7) Dowsland, K. \& Dowsland, W. (1992). Packing problems. European Journal of Operational Research, 56, 2-14.

(8) Dyckhoff, H. (1990). A typology of cutting and packing problems. European Journal of the Operational Research, 44, 145-159.

(9) Dyckhoff, H. \& Finke, U. (1992). Cutting and packing in production and distribution. Springer-Verlag Co., Heildelberg.

(10) Dyckhoff, H.; Scheithauer, G. \& Terno, J. (1997). Cutting and packing. In: Annotated bibliographies in combinatorial optimisation [edited by M. Amico, F. Maffioli and S. Martello], John Wiley \& Sons, New York, NY, 393-414.

(11) Garcia, V. (1996). Geração de padrões de corte de chapas de fibra de madeira reconstituída. Dissertação de Mestrado, Departamento de Engenharia de Produção, UFSCar, São Carlos, SP.

(12) Gilmore, P. \& Gomory, R. (1961). A linear programming approach to the cutting stock problem. European Journal of the Operational Research, 9, 849-859.

(13) Gilmore, P. \& Gomory, R. (1963). A linear programming approach to the cutting stock problem - Part II. European Journal of the Operational Research, 11, 863-888.

(14) Gilmore, P. \& Gomory, R. (1965). Multistage cutting stock problems of two and more dimensions. European Journal of the Operational Research, 13, 94-120.

(15) Herz, J.C. (1972). Recursive computational procedure for two-dimensional cutting. IBM Journal of Research and Development, 16, 462-469.

(16) Hifi, M. (2002). Special issue: Cutting and packing problems. Studia Informatica Universalis, 2(1), 1-161.

(17) Hinxman, A.I. (1980). The trim loss and assortment problems: A survey. European Journal of Operational Research, 5, 8-18.

(18) Lodi, A.; Martello, S. \& Monaci, M. (2002). Two-dimensional packing problems: a survey. European Journal of Operational Research, 141, 241-252.

(19) Martello, S. \& Toth, P. (1990). Knapsack problems: Algorithms and computer implementations. J. Wiley \& Sons, Chichester.

(20) Martello, S. (1994). Special issue: Knapsack, packing and cutting, Part II: Multidimensional knapsack and cutting stock problems. INFOR, 32(4).

(21) Morabito, R. (1992). Uma abordagem em grafo-e/ou para o problema do empacotamento: Aplicação ao carregamento de paletes e contêineres. Tese de Doutorado, EESC-USP, São Carlos, SP.

(22) Morabito, R. \& Arenales, M. (1992). Um exame dos problemas de corte e empacotamento. Pesquisa Operacional, 12(1), 1-20.

(23) Morabito, R. \& Garcia, V. (1998a). The cutting stock problem in a hardboard industry: A case study. Computers \& Operations Research, 25(6), 469-485. 
(24) Morabito, R. \& Garcia, V. (1998b). Uma abordagem para o problema de cortes de chapas de fibra de madeira reconstituída. Pesquisa Operacional, 18(1), 37-57.

(25) Morabito, R. \& Arenales, M. (2000). Optimizing the cutting of stock plates in a furniture company. International Journal of Production Research, 38(12), 2725-2742.

(26) Pileggi, G.F. (2002). Abordagens para otimização integrada dos problemas de geração e sequenciamento de padrões de corte. Tese de Doutorado, ICMC-USP, São Carlos, SP.

(27) Pileggi, G., Morabito, R. \& Arenales, M. (2005). Abordagens para otimização integrada dos problemas de geração e seqüenciamento de padrões de corte: caso unidimensional. Pesquisa Operacional, 25(3), 417-447.

(28) Pinto, M.J. (2004). Algumas contribuições à resolução do problema de corte integrado ao problema de seqüenciamento dos padrões. Tese de Doutorado, Laboratório de Computação e Matemática Aplicada, INPE, São José dos Campos, SP.

(29) SICUP (2004). Special Interest Group on Cutting and Packing. $<$ http://www.apdio.pt/sicup/>.

(30) Silva, R. \& Morabito, R. (2004). Otimização da programação de cargas de forno em uma fábrica de fundição em aço-inox. Gestão \& Produção, 11(1).

(31) Silveira, R. \& Morabito, R. (2002). Um método heurístico baseado em programação dinâmica para o problema de corte bidimensional guilhotinado restrito. Gestão \& Produção, 9(1), 78-92.

(32) Sweeney, P. \& Paternoster, E. (1992). Cutting and packing problems: A categorized, application-oriented research bibliography. European Journal of the Operational Research, 43, 691-706.

(33) Yanasse, H. (1997). On a pattern sequencing problem to minimise the maximum number of open stacks. European Journal of Operational Research, 100(3), 454-463.

(34) Yanasse, H.; Zinober, A. \& Harris, R. (1991). Two-dimensional cutting stock with multiple stock sizes. Journal of the Operational Research Society, 42, 673-683.

(35) Yuen. B.J. (1995). Improved heuristics for sequencing cutting patterns. European Journal of Operational Research, 87, 57-64.

(36) Wang, P. \& Waescher, G. (2002). Special issue on cutting and packing. European Journal of Operational Research, 141(2), 239-469. 